\title{
First Quarter Chemical Borehole Studies in the Drift Scale Test
}

\author{
L. DeLoach \\ R. Martinelli \\ M. Chiarappa \\ B. Glassley
}

May 19, 1998

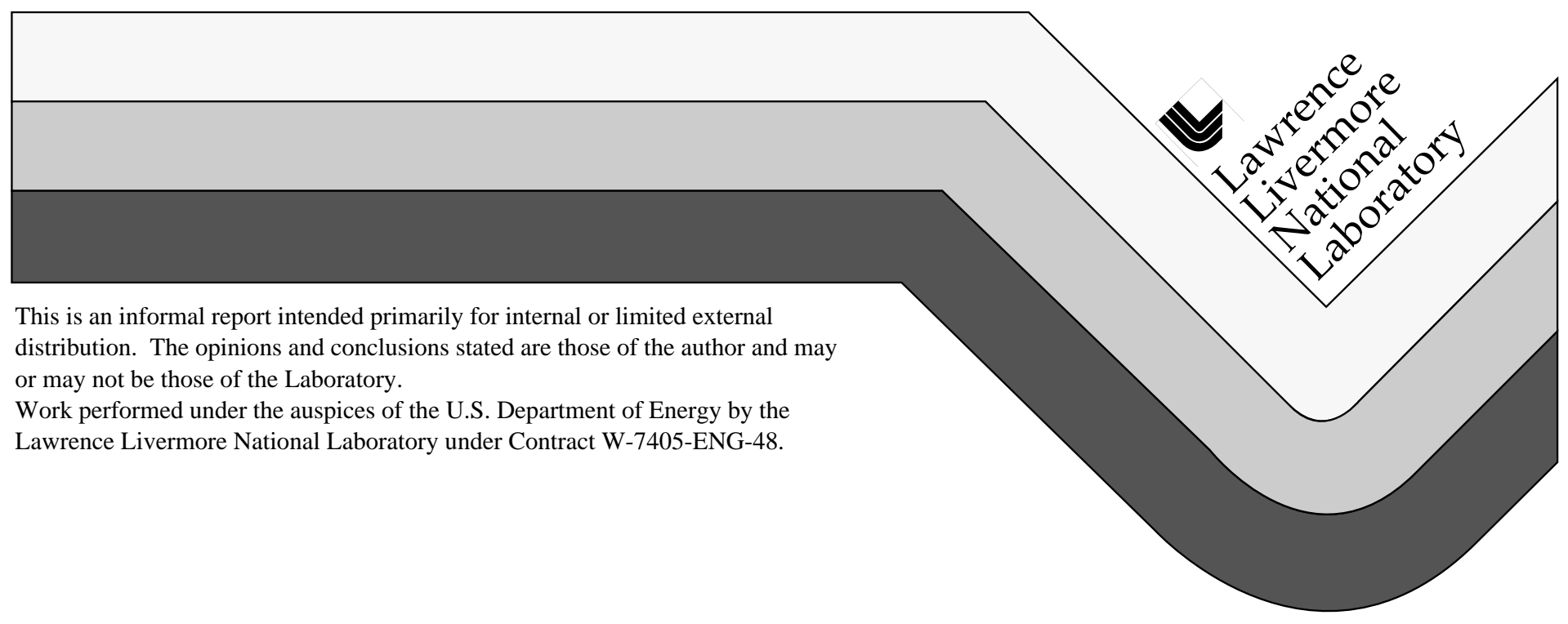




\section{DISCLAIMER}

This document was prepared as an account of work sponsored by an agency of the United States Government. Neither the United States Government nor the University of California nor any of their employees, makes any warranty, express or implied, or assumes any legal liability or responsibility for the accuracy, completeness, or usefulness of any information, apparatus, product, or process disclosed, or represents that its use would not infringe privately owned rights. Reference herein to any specific commercial product, process, or service by trade name, trademark, manufacturer, or otherwise, does not necessarily constitute or imply its endorsement, recommendation, or favoring by the United States Government or the University of California. The views and opinions of authors expressed herein do not necessarily state or reflect those of the United States Government or the University of California, and shall not be used for advertising or product endorsement purposes.

This report has been reproduced directly from the best available copy.

Available to DOE and DOE contractors from the Office of Scientific and Technical Information P.O. Box 62, Oak Ridge, TN 37831

Prices available from (423) 576-8401

Available to the public from the National Technical Information Service

U.S. Department of Commerce 5285 Port Royal Rd. Springfield, VA 22161 


\title{
First Quarter Chemical Borehole Studies in the Drift Scale Test
}

\author{
milestone SP2640M4 \\ Rev. 1, May 19,1998 \\ Laura DeLoach, Roger Martinelli, Marina Chiarappa, and Bill Glassley \\ Lawrence Livermore National Laboratory
}

\section{Introduction}

The chemistry boreholes of the Drift Scale Test (DST) have been designed to gather geochemical information and assess the impact of thermal perturbations on gas and liquid phases present in pore spaces and fractures within the rock. There are a total of ten boreholes dedicated to these chemical studies. Two arrays of five boreholes each were drilled from the access/observation drift (AOD) in planes which run normal to the heater drift and which are located approximately 15 and $45 \%$ of the way along the length of the drift as measured from the bulkhead. The boreholes each have a length of about 40 meters and have been drilled at low angles directed just above or just below the heater plane. In each array, three boreholes are directed at increasingly steeper angles $(<25 \infty)$ above the line of wing heaters and two are directed at shallow angles below the wing heater plane.[1]

To assess the geochemical changes as a function of time and position, the boreholes have each been lined with two different sampling liner systems. Both employ SEAMIST liner technology (Science Engineering Associate Membrane In-situ Sampling Technology) which is an instrumentation and fluid sampler emplacement technique designed for in-situ hydrologic characterization and monitoring investigations. It uses an inverting, pneumatically-deployed tubular membrane to install sampling devices and instruments in uncased boreholes. For each chemistry borehole of the DST, one SEAMIST liner has been installed with Teflon tubing lines run to various depths and ending at the collar of the hole with a port for sampling the gases originating from the rock walls. In the same hole and adjacent to this liner, a second liner has been installed with a linear array of highly absorbent pads for the collection of pore and condensate water samples; electrical resistance is measured in the pads to indicate wetness. The gas sampling liner is installed and pressurized to effectively seal the rock walls of the borehole and thereby limit the accessibility of the sampling sites to the air from the drift. The fluids are collected on 10 pads positioned approximately every 4 meters along the length of the hole, and six Teflon tubing lines (three pairs) are equidistantly-placed along the length to collect the rock gases. The positions of the pads and ports within the boreholes are summarized in Table 1.

Gas samples and damp pads are collected from the boreholes and taken for chemical analyses. The gaseous phases are analyzed for the volume percent of atmospheric constituents (predominantly N2, O2, Ar, and CO2). The pads are analyzed for a suite of ions typical of the total dissolved solids found in ground water samples from the vicinity of Yucca Mountain. The chemical composition of the gases and liquids will be analyzed throughout the heating phase of the Drift Scale Test and the results will be considered as a function of time and location with respect to the heaters in the heated drift. The schedule and the analytical protocols for the two systems are described in this report. The available results for the first few months of heating are presented. 


\section{SEAMIST Gas Sampling in the DST}

The general procedure for collecting gases from the chemistry boreholes is to use gas-tight syringes to draw in gas through the Teflon tubing and to inject the sample into previouslyevacuated, stainless steel vessels. The gas initially present in the tubing is expected to represent a mixture of the rock gas from pores and fractures in the borehole walls as well as atmospheric mine air diffused in from the sampling port that opens into the AOD. In order to collect sample rich in the rock gases, the tubing has to be depleted of this ìcompositionally-mixedî air that is present initially and refilled with the desired rock gases from the borehole walls. This process occurs when the gas-tight syringe creates a slight vacuum on the tubing as the plunger is drawn back during sample collection, then the gases from the rock pore spaces and fractures refill the line to equalize the pressure. Samples enriched in the rock gases from the walls of the borehole would be those pulled after multiple draws of the syringe.

A series of gas samples are collected for a given borehole and port as follows: the volume of gas determined to be present in the tubing (estimated from the diameter and length of the tube) is first removed in several small aliquots which are individually collected into evacuated vessels. With the full volume of the line removed, two additional samples are drawn from the same port, and these are collected into two more stainless steel vessels. All of these samples are returned for analyses. For comparison, gas samples of the AOD mine air are also collected directly into the evacuated stainless steel vessels simply by opening the main valve for filling, and heater drift atmosphere is collected from a sampling port accessible on the bulkhead itself. All vessels are labeled with Sample Management Facility (SMF) identifiers and packed for their transport to the gas mass spectrometry lab at LLNL.

\section{Gas Analysis by Gas Mass Spectrometry}

The collected gas samples are analyzed on a VG 30-01 gas analytical mass spectrometer for the volume percent of $\mathrm{N} 2, \mathrm{O} 2, \mathrm{Ar}, \mathrm{CO} 2, \mathrm{CO}, \mathrm{CH} 4, \mathrm{He}$ and $\mathrm{H} 2$. In addition, the presence of molecules with molecular weight of 160 or less are identified from the scan, but not quantified. The determinations are made by the mass abundance and the cracking pattern for the various components. Levels of detection for the VG 30-01 are $0.01 \%$, with the exception of $\mathrm{CO}$ which is detectable at levels of $0.05 \%$. A standard deviation for each gas component is determined from the differences of the predicted partial pressures and those observed. Water vapor itself is not analyzed.

Each trip to the DST requires multiple gas sampling vessels to be available, clean and evacuated. As a consequence, samples cannot be archived, nor held for additional future analyses. The LLNL gas mass spectrometry lab, currently performs all gas analyses, as well as evacuation and leak-testing of the vessels used for these gas studies.

\section{SEAMIST Sampling of Pore Fluids in the DST}

The composition of water in the pore space and moving through the fractures of rock during the DST will be assessed from the fluid which contacts the array of absorbent pads of each SEAMIST liner system. The pads are situated approximately every 4 meters along the length of each borehole and tightly pressed against the rock walls of the borehole with the inflation of the sealing liner. Any fluid and/or condensate which result from the heating activities, may contact and be wicked into the pads at the various locations. Thus, the potential to analyze the fluid chemistry with respect to time and space is inherently built into the experimental design. 
To determine whether pads have taken on moisture during the test, a measurement is made and recorded by the data collection system (DCS) which directly relates to the padís electrical resistance. The electrical resistance of the pads would vary significantly depending on whether they are measured when dry or wet. Thus, plots of resistance over time may be used to determine when the resistance has dropped dramatically for any of the pads thereby reflecting the wetting process.

Contrary to the sampling strategy for the gas collection in the DST, the collection of water (i.e. the absorbent pads) from the SEAMIST liner system requires the complete removal of a liner from the particular borehole. Each of the pads are collected from the liner (not just the suspected "damp" ones) and another liner with clean pads is reinstalled. During collection the pads need to be minimally handled and exposed in order to prevent contamination and limit evaporation. On the other hand, it will be important to accurately document the condition of the pads with respect to apparent moisture content (e.g. comparing wet and dry weights), adhering rock fragments (potentially affecting both weight and analyte concentration), apparent distribution of moisture across a pad (if inhomogeneous), and other physical observations which may be relevant to the analyses to be performed. The pads will then be stored and transferred in clean, air-tight bags and made available for immediate preparation and analysis at qualified chemistry labs at LLNL .

\section{SEAMIST Pad Analytical Strategy}

The water composition determined from the SEAMIST pads collected in the DST will be analyzed using several methods and therefore will necessitate sectioning each of the pads among the tests to obtain complete analytical data for the different locations represented by the pads characterized. The suite of inorganics to be included for analysis can be grouped into three categories: 1) metals or cations , 2) anions, and 3) carbonates. The metals are: Aluminum (Al), Boron (B), Calcium (Ca), Iron (Fe), Magnesium (Mg), Lithium (Li), Sodium (Na), Potassium (K), Sulfur (S), Silicon (Si), and Strontium (Sr). The oxidative states of the metals are not critical since the metal analysis will quantify the total metals present regardless of the oxidative state species (although it is assumed that they are in the cation conformation). The anions are Fluoride (F-), Chloride (Cl-), Bromide (Br-), Nitrite (NO2-), Nitrate (NO3-), Phosphate (PO43-), and Sulfate (SO42-). The final analyte is Carbonate (CO32-). The oxidative state of the anions is critical, because analyses will be specifically for the anion species. Carbonates will be analyzed separately from the other anions due to analytical difficulties in performing carbonate analysis along with the analyses of the other analytes.

The analytical method of Inductively Coupled Plasma (ICP) will be utilized to obtain cation concentrations, including $\mathrm{Al}, \mathrm{B}, \mathrm{Ca}, \mathrm{Fe}, \mathrm{Mg}, \mathrm{Li}, \mathrm{Na}, \mathrm{K}, \mathrm{S}, \mathrm{Si}$, and $\mathrm{Sr}$. Samples destined for ICP will be prepared through an acid extraction procedure. The anions will be analyzed by Ion Chromatography (IC). IC will provide the concentrations of F-, Cl-, Br-, NO2-, NO3-, PO43-, and SO42-. Samples destined for IC analyses will be prepared by a water extraction procedure. For CO32- analyses separate pad sections will be submitted for an infrared (IR) analysis technique where $\mathrm{CO} 2$ is liberated from the carbonate and quantified. The carbon dioxide generated by acidification of the pad material is directly proportional to the carbonate present. For each technique employed, appropriate controls and matrix blanks will be documented. 


\section{Available Sample Analyses from DST First-Quarter Heating}

Gas sampling from the chemical study boreholes in the DST has occurred approximately every 4-6 weeks, in coordination with the air permeability studies and tracer gas testing conducted by LBNL. The focus of the sampling efforts has been the lower borehole array (series ESF-HD-CHE- 1,2Ö5), located closest to the bulkhead end of the heater drift. Samples have been collected from those boreholes that are closest to the heaters, and from the gas sampling ports in them that are most proximal to the heaters. The data from the first two collecting trips since heaters were turned on are presented in Tables 2 and 3. The baseline data from a previously submitted report are repeated here for comparison; see Table 4. These data must all be considered preliminary at this time, since the complete QA requirements have not been satisfied. Nevertheless, all data were collected on a fully calibrated system by acceptable methods employed in gas mass spectrometry labs and are expected to be Q-pedigreed according to QARD procedures.

Sample designations used in the milestone reports utilize an abbreviated borehole number (52-56 and 69-73) and reference to one of six possible ports located on each liner. The actual sample locations may be determined using the information provided in Table 1. The samples increase alphabetically for multiple and sequential samples drawn from a single hole and port; according to the procedure described. All samples can also be identified with a unique SMF bar-coded number which is tracked in controlled notebook \#00342. Finally, atmospheric gas samples collected from within Alcove 5 are listed according to the location drawn, so that OD refers to the observation drift in the vicinity of the lower series of chemistry boreholes, $\mathrm{CD}$ refers to the connecting drift or the area between the bulkhead and the AOD, and HD is a reference to the heater drift samples collected from the ports accessible in the bulkhead itself.

The data collected to date are very similar to atmospheric chemistry, with slightly higher $\mathrm{CO} 2$ content. Atmospheric CO2 is 0.033 ( 0.001 per cent by volume (exclusive of water vapor) as generally reported (e.g. in the CRC Handbook of Chemistry and Physics). The data for the chemistry boreholes reflect a CO2 content which averages $\sim 0.06 \%$.

Nevertheless, these values are similar to the average value observed for the $\mathrm{CO} 2$ content sampled in the observation drift.

The data are currently only available for the baseline and the first two months of the test. Figure 1 is a plot of the $\mathrm{CO} 2$ content for representative gas samples collected from particular sampling sites over time. Not surprisingly, trends in the data are not yet indicated. Ultimately, the intent will be to examine composition as a function of time and space, but more data are needed.

To date, the absorbent liner systems used for water collection have not been pulled. Although the DCS records numbers which are related to each padís resistance, the information are not treated as data per se; the plots of resistance with respect to time are studied to determine whether significant changes in resistance have been measured, and accordingly, whether the trends result from wetting of the pads. Interpretation of these resistance plots, however, has not been straightforward during this first quarter of heating for several reasons. Spikes have been observed in the plots of resistance which have been traced to sudden loss of pressure, as when the sealing liners are deflated for any period of time. In certain instances, broken connections appear to be indicated, presumably as a consequence of difficulties encountered entering the liners into the boreholes. Furthermore, the instrumentation systems were not complete in all boreholes at the start of heating, nor were connections completed with the DCS prior to heater turn-on for the baseline readings. For these reasons, the first absorber liners will be pulled and replaced at convenient 
intervals until supplementary data can be collected from laboratory studies of the absorber pads themselves.

\section{References}

[1]. Civilian Radioactive Waste Management System and Operating Contractor (OCRWM M\&O), 1996, ìTest, design, plans, and layout for the first ESF thermal test,î Rev. 1, BAB000000-01717-4600-00025, TRW Environmental Safety System, Inc., Las Vegas, NV 89109. 
Figure 1. The average $\mathrm{CO}_{2}$ concentration for representative borehole gas samples and for drift atmospheres during first quarter heating.

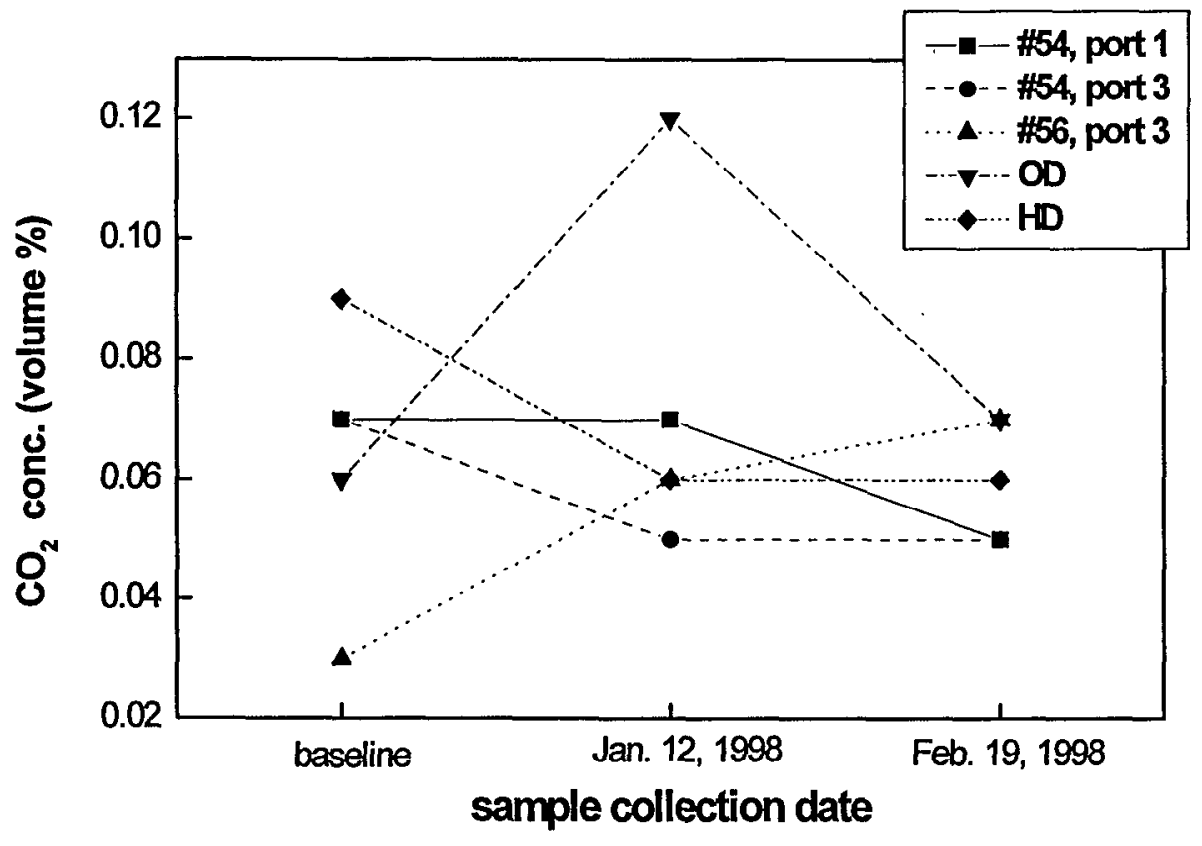


Table 1. Distance of gas sampling ports and absorbant pads (in meters) from the collar of each borehole.

\begin{tabular}{|c|c|c|c|c|c|c|c|c|c|c|}
\hline $\begin{array}{l}\text { ESF-HD-CHE- } \\
\text { sensors }\end{array}$ & $\begin{array}{c}\text { Hole \#52 } \\
\text {...CHE-1 }\end{array}$ & $\begin{array}{c}\text { Hole \#53 } \\
\text {...CHE-2 } \\
\end{array}$ & $\begin{array}{c}\text { Hole \#54 } \\
\text {...CHE-3 }\end{array}$ & $\begin{array}{c}\text { Hole \#55 } \\
\text {...CHE-4 }\end{array}$ & $\begin{array}{c}\text { Hole \#56 } \\
\text {...CHE-5 }\end{array}$ & $\begin{array}{c}\text { Hole \#69 } \\
\text {...CHE-6 }\end{array}$ & $\begin{array}{c}\text { Hole \#70 } \\
\ldots \text {...CHE-7 }\end{array}$ & $\begin{array}{c}\text { Hole \#71 } \\
\ldots \text {...CHE-8 }\end{array}$ & $\begin{array}{c}\text { Hole \#72 } \\
\text {...CHE-9 }\end{array}$ & $\begin{array}{l}\text { Hole \#73 } \\
\text {...CHE-10 }\end{array}$ \\
\hline ports 1,2 & none* & none & 35.0 & $\overline{31.0}$ & 35.0 & 34.0 & 35.0 & 35.1 & 35.1 & 35.1 \\
\hline ports 3,4 & 17.1 & 15.0 & 18.9 & 18.9 & 18.9 & 18.0 & 18.9 & 18.9 & 18.9 & 18.9 \\
\hline ports 5,6 & 1.2 & 1.2 & 3.1 & 3.1 & 3.1 & 2.1 & 3.1 & 3.1 & 3.1 & 3.1 \\
\hline absorber 1 & none & none & 39.0 & none & none & none & none & 39.0 & none & none \\
\hline absorber 2 & none & none & 35.1 & 35.1 & 35.1 & none & none & 35.1 & 35.1 & none \\
\hline absorber 3 & 31.1 & none & 31.1 & 31.1 & 31.1 & none & none & 31.1 & 31.1 & 31.0 \\
\hline absorber 4 & 27.1 & none & 27.1 & 27.1 & 27.1 & none & none & 27.1 & 27.1 & 27.1 \\
\hline absorber 5 & 22.9 & none & 22.9 & 22.9 & 22.9 & none & none & 22.9 & 22.9 & 22.9 \\
\hline absorber 6 & 18.9 & none & 18.9 & 18.9 & 18.9 & 18.9 & 19.0 & 18.9 & 18.9 & 18.9 \\
\hline absorber 7 & 14.9 & 15.0 & 14.9 & 14.9 & 14.9 & 15.0 & 15.0 & 14.9 & 14.9 & 14.9 \\
\hline absorber 8 & 11.0 & 11.0 & 11.0 & 11.0 & 11.0 & 11.0 & 11.0 & 11.0 & 11.0 & 11.0 \\
\hline absorber 9 & 17.1 & 7.0 & 7.0 & 7.0 & 7.0 & 7.0 & 7.0 & 7.0 & 7.0 & 7.0 \\
\hline absorber 10 & 3.1 & 3.0 & 3.1 & 3.1 & 3.1 & 3.0 & 3.0 & 3.1 & 3.1 & 3.1 \\
\hline
\end{tabular}

* the designation "none" results from a shortened liner with respect to other holes: in one case the hole itself is shorter (\#55), but most cases are because the liner was blocked from full extension. 
Table 2. Jan. 13, 1998 gas sample analyses determined by analytical gas mass spectrometry.* All results are expressed in mole (volume) percent.

\begin{tabular}{|c|c|c|c|c|c|c|c|c|c|}
\hline Sample Name & Nitrogen & Oxygen & Argon & Carbon Dioxide & Carbon Monoxlde & Methane & Holium & Hydrogen & Total \% \\
\hline $54-1 A$ & $76.69 \%$ & $22.33 \%$ & $0.95 \%$ & $0.03 \%$ & $<0.50$ & $<0.01$ & $<0.01$ & $<0.01$ & $100.0 \%$ \\
\hline $54-1 B$ & $77.36 \%$ & $21.67 \%$ & $0.93 \%$ & $0.04 \%$ & $<0.50$ & $<0.01$ & $<0.01$ & $<0.01$ & $100.0 \%$ \\
\hline $54-1 \mathrm{C}$ & $77.04 \%$ & $21.99 \%$ & $0.93 \%$ & $0.04 \%$ & $<0.50$ & $<0.01$ & $<0.01$ & $<0.01$ & $100.0 \%$ \\
\hline $54-1 D$ & $77.02 \%$ & $22.00 \%$ & $0.93 \%$ & $0.05 \%$ & $<0.50$ & $<0.01$ & $<0.01$ & $<0.01$ & $100.0 \%$ \\
\hline 54-1E & $76.91 \%$ & $22.11 \%$ & $0.93 \%$ & $0.04 \%$ & $<0.50$ & $<0.01$ & $<0.01$ & $<0.01$ & $100.0 \%$ \\
\hline $54-1 F$ & $76.90 \%$ & $22.09 \%$ & $0.94 \%$ & $0.07 \%$ & $<0.50$ & $<0.01$ & $<0.01$ & $<0.01$ & $100.0 \%$ \\
\hline & & & & & & & & & \\
\hline $54-3 A$ & $76.86 \%$ & $22.15 \%$ & $0.93 \%$ & $0.06 \%$ & $<0.50$ & $<0.01$ & $<0.01$ & $<0.01$ & $100.0 \%$ \\
\hline $54-3 \mathrm{~B}$ & $76.88 \%$ & $22.12 \%$ & $0.93 \%$ & $0.08 \%$ & $<0.50$ & $<0.01$ & $<0.01$ & $<0.01$ & $100.0 \%$ \\
\hline $54-3 C$ & $77.58 \%$ & $21.45 \%$ & $0.92 \%$ & $0.04 \%$ & $<0.50$ & $<0.01$ & $<0.01$ & $<0.01$ & $100.0 \%$ \\
\hline $54-3 \mathrm{D}$ & $77.48 \%$ & $21.56 \%$ & $0.91 \%$ & $0.05 \%$ & $<0.50$ & $<0.01$ & $<0.01$ & $<0.01$ & $100.0 \%$ \\
\hline $54-3 E$ & $77.37 \%$ & $21.66 \%$ & $0.92 \%$ & $0.06 \%$ & $<0.50$ & $<0.01$ & $<0.01$ & $<0.01$ & $100.0 \%$ \\
\hline $54-3 \mathrm{~F}$ & $77.33 \%$ & $21.70 \%$ & $0.92 \%$ & $0.05 \%$ & $<0.50$ & $<0.01$ & $<0.01$ & $<0.01$ & $100.0 \%$ \\
\hline & & & & & & & & & \\
\hline $55-1 A$ & $77.37 \%$ & $21.66 \%$ & $0.92 \%$ & $0.05 \%$ & $<0.50$ & $<0.01$ & $<0.01$ & $<0.01$ & $100.0 \%$ \\
\hline $55-1 B$ & $77.77 \%$ & $21.26 \%$ & $0.92 \%$ & $0.05 \%$ & $<0.50$ & $<0.01$ & $<0.01$ & $<0.01$ & $100.0 \%$ \\
\hline $55-1 C$ & $77.73 \%$ & $21.31 \%$ & $0.91 \%$ & $0.05 \%$ & $<0.50$ & $<0.01$ & $<0.01$ & $<0.01$ & $100.0 \%$ \\
\hline 55-1D & $77.50 \%$ & $21.53 \%$ & $0.91 \%$ & $0.05 \%$ & $<0.50$ & $<0.01$ & $<0.01$ & $<0.01$ & $100.0 \%$ \\
\hline $55-1 E$ & $77.54 \%$ & $21.50 \%$ & $0.91 \%$ & $0.05 \%$ & $<0.50$ & $<0.01$ & $<0.01$ & $<0.01$ & $100.0 \%$ \\
\hline 55-1F & $77.65 \%$ & $21.41 \%$ & $0.89 \%$ & $0.06 \%$ & $<0.50$ & $<0.01$ & $<0.01$ & $<0.01$ & $100.0 \%$ \\
\hline $55-3 A$ & $77.43 \%$ & $21.60 \%$ & $0.91 \%$ & $0.06 \%$ & $<0.50$ & $<0.01$ & $<0.01$ & $<0.01$ & $100.0 \%$ \\
\hline 55-3B & $77.32 \%$ & $21.71 \%$ & $0.92 \%$ & $0.05 \%$ & $<0.50$ & $<0.01$ & $<0.01$ & $<0.01$ & $100.0 \%$ \\
\hline $55-3 C$ & $77.46 \%$ & $21.58 \%$ & $0.91 \%$ & $0.05 \%$ & $<0.50$ & $<0.01$ & $<0.01$ & $<0.01$ & $100.0 \%$ \\
\hline $55-3 D$ & $77.46 \%$ & $21.53 \%$ & $0.01 \%$ & $0.09 \%$ & $<0.50$ & $<0.01$ & $<0.01$ & $<0.01$ & $100.0 \%$ \\
\hline $55-3 E$ & $77.34 \%$ & $21.69 \%$ & $0.91 \%$ & $0.06 \%$ & $<0.50$ & $<0.01$ & $<0.01$ & $<0.01$ & $100.0 \%$ \\
\hline $55-3 F$ & $77.65 \%$ & $21.41 \%$ & $0.90 \%$ & $0.04 \%$ & $<0.50$ & $<0.01$ & $<0.01$ & $<0.01$ & $100.0 \%$ \\
\hline & & & & & & & & & \\
\hline $56-1 \mathrm{~A}$ & $77.81 \%$ & $21.26 \%$ & $0.90 \%$ & $0.04 \%$ & $<0.50$ & $<0.01$ & $<0.01$ & $<0.01$ & $100.0 \%$ \\
\hline 56-1B & $77.61 \%$ & $21.45 \%$ & $0.90 \%$ & $0.04 \%$ & $<0.50$ & $<0.01$ & $<0.01$ & $<0.01$ & $100.0 \%$ \\
\hline 365 & 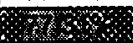 & 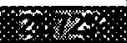 & \% & $105 \%$ & 60 & son & $0 \%$ & 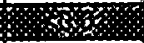 & \\
\hline $56-10$ & $77.53 \%$ & $21.51 \%$ & $0.91 \%$ & $0.05 \%$ & $<0.50$ & $<0.01$ & $<0.01$ & $<0.01$ & $100.0 \%$ \\
\hline $56-1 E$ & $77.48 \%$ & $21.56 \%$ & $0.91 \%$ & $0.05 \%$ & $<0.50$ & $<0.01$ & $<0.01$ & $<0.01$ & $100.0 \%$ \\
\hline $56-1 F$ & $\mathbf{7 7 . 3 4 \%}$ & $21.71 \%$ & $0.91 \%$ & $0.05 \%$ & $<0.50$ & $<0.01$ & $<0.01$ & $<0.01$ & $100.0 \%$ \\
\hline & & & & & & & & & \\
\hline $56-3 A$ & $76.73 \%$ & $22.30 \%$ & $0.92 \%$ & $0.06 \%$ & $<0.50$ & $<0.01$ & $<0.01$ & $<0.01$ & $100.0 \%$ \\
\hline $56-3 B$ & $77.35 \%$ & $21.70 \%$ & $0.90 \%$ & $0.05 \%$ & $<0.50$ & $<0.01$ & $<0.01$ & $<0.01$ & $100.0 \%$ \\
\hline $56-3 C$ & $77.37 \%$ & $21.66 \%$ & $0.92 \%$ & $0.05 \%$ & $<0.50$ & $<0.01$ & $<0.01$ & $<0.01$ & $100.0 \%$ \\
\hline 63 & 21 & $\alpha \ldots$ & 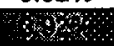 & 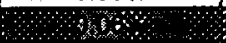 & 83 & 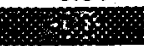 & +4 & 78 & Ho $1 \mathrm{~A}$ \\
\hline $56-3 \mathrm{E}$ & $76.83 \%$ & $22.12 \%$ & $0.83 \%$ & $0.12 \%$ & $<0.50$ & $<0.01$ & $<0.01$ & $<0.01$ & $100.0 \%$ \\
\hline 56 & & 285 & $8 \%$ & 5.6 & 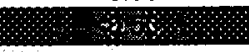 & 58 & 6 & 48 & 86 \\
\hline HD-1 & $77.54 \%$ & $21.49 \%$ & $0.91 \%$ & $0.06 \%$ & $<0.50$ & $<0.01$ & $<0.01$ & $<0.01$ & $100.0 \%$ \\
\hline HD-2 & $77.46 \%$ & $21.56 \%$ & $0.92 \%$ & $0.06 \%$ & $<0.50$ & $<0.01$ & $<0.01$ & $<0.01$ & $100.0 \%$ \\
\hline $\mathrm{HD}-3$ & $77.43 \%$ & $21.61 \%$ & $0.91 \%$ & $0.05 \%$ & $<0.50$ & $<0.01$ & $<0.01$ & $<0.01$ & $100.0 \%$ \\
\hline & & & & & & & & & \\
\hline$\overline{O D-1}$ & $77.43 \%$ & $21.54 \%$ & $0.91 \%$ & $0.12 \%$ & $<0.50$ & $<0.01$ & $<0.01$ & $<0.01$ & $100.0 \%$ \\
\hline & & & & & & & & & \\
\hline ua & & 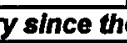 & $\mathrm{re}$ & 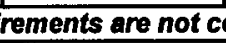 & & & & & \\
\hline
\end{tabular}


Table 3. Feb. 19, 1998 gas sample analyses determined by analytical gas mass spectrometry.* All results are expressed in mole (volume) percent.

\begin{tabular}{|c|c|c|c|c|c|c|c|c|c|}
\hline Sample Name & Nitrogen & Oxygen & Argon & Carbon Dloxlde & Carbon Monoxldo & Methane & Hollum & Hydrogen & Total \% \\
\hline $54-1 \mathrm{~A}$ & $77.61 \%$ & $21.41 \%$ & $0.91 \%$ & $0.07 \%$ & $<0.50$ & $<0.01$ & $<0.01$ & $<0.01$ & $100.0 \%$ \\
\hline 64-1B & $77.29 \%$ & $21.74 \%$ & $0.01 \%$ & $0.06 \%$ & $<0.50$ & $<0.01$ & $<0.01$ & $<0.01$ & $100.0 \%$ \\
\hline $54-1 \mathrm{C}$ & $77.20 \%$ & $21.84 \%$ & $0.91 \%$ & $0.05 \%$ & $<0.50$ & $<0.01$ & $<0.01$ & $<0.01$ & $100.0 \%$ \\
\hline 54-1D & $77.23 \%$ & $21.80 \%$ & $0.91 \%$ & $0.05 \%$ & $<0.50$ & $<0.01$ & $<0.01$ & $<0.01$ & $100.0 \%$ \\
\hline $54-1 E$ & $77.41 \%$ & $21.62 \%$ & $0.91 \%$ & $0.05 \%$ & $<0.50$ & $<0.01$ & $<0.01$ & $<0.01$ & $100.0 \%$ \\
\hline 54-1F & $77.33 \%$ & $21.72 \%$ & $0.91 \%$ & $0.04 \%$ & $<0.50$ & $<0.01$ & $<0.01$ & $<0.01$ & $100.0 \%$ \\
\hline $54-3 A$ & $77.68 \%$ & $21.34 \%$ & $0.93 \%$ & $0.05 \%$ & $<0.50$ & $<0.01$ & $<0.01$ & $<0.01$ & $100.0 \%$ \\
\hline $54-3 B$ & $77.53 \%$ & $21.50 \%$ & $0.93 \%$ & $0.05 \%$ & $<0.50$ & $<0.01$ & $<0.01$ & $<0.01$ & $100.0 \%$ \\
\hline 54-3C & $77.41 \%$ & $21.61 \%$ & $0.93 \%$ & $0.05 \%$ & $<0.50$ & $<0.01$ & $<0.01$ & $<0.01$ & $100.0 \%$ \\
\hline $54-3 D$ & $77.48 \%$ & $21.55 \%$ & $0.93 \%$ & $0.05 \%$ & $<0.50$ & $<0.01$ & $<0.01$ & $<0.01$ & $100.0 \%$ \\
\hline $54-3 E$ & $77.43 \%$ & $21.59 \%$ & $0.93 \%$ & $0.05 \%$ & $<0.50$ & $<0.01$ & $<0.01$ & $<0.01$ & $100.0 \%$ \\
\hline 54-3F & $77.41 \%$ & $21.62 \%$ & $0.93 \%$ & $0.05 \%$ & $<0.50$ & $<0.01$ & $<0.01$ & $<0.01$ & $100.0 \%$ \\
\hline $55-1 A$ & $77.38 \%$ & $21.65 \%$ & $0.93 \%$ & $0.05 \%$ & $<0.50$ & $<0.01$ & $<0.01$ & $<0.01$ & $100.0 \%$ \\
\hline $55-1 \mathrm{~B}$ & $77.37 \%$ & $21.65 \%$ & $0.93 \%$ & $0.05 \%$ & $<0.50$ & $<0.01$ & $<0.01$ & $<0.01$ & $100.0 \%$ \\
\hline $55-1 \mathrm{C}$ & $77.38 \%$ & $21.65 \%$ & $0.92 \%$ & $0.05 \%$ & $<0.50$ & $<0.01$ & $<0.01$ & $<0.01$ & $100.0 \%$ \\
\hline $55-1 D$ & $77.25 \%$ & $21.79 \%$ & $0.92 \%$ & $0.05 \%$ & $<0.50$ & $<0.01$ & $<0.01$ & $<0.01$ & $100.0 \%$ \\
\hline 55-1E & $77.28 \%$ & $21.75 \%$ & $0.92 \%$ & $0.05 \%$ & $<0.50$ & $<0.01$ & $<0.01$ & $<0.01$ & $100.0 \%$ \\
\hline 55-1F & $77.18 \%$ & $21.85 \%$ & $0.93 \%$ & $0.05 \%$ & $<0.50$ & $<0.01$ & $<0.01$ & $<0.01$ & $100.0 \%$ \\
\hline $55-3 A$ & $77.22 \%$ & $21.81 \%$ & $0.93 \%$ & $0.04 \%$ & $<0.50$ & $<0.01$ & $<0.01$ & $<0.01$ & $100.0 \%$ \\
\hline $55-3 B$ & $77.23 \%$ & $21.74 \%$ & $0.92 \%$ & $0.10 \%$ & $<0.50$ & $<0.01$ & $<0.01$ & $<0.01$ & $100.0 \%$ \\
\hline $55-3 C$ & $77.27 \%$ & $21.76 \%$ & $0.93 \%$ & $0.05 \%$ & $<0.50$ & $<0.01$ & $<0.01$ & $<0.01$ & $100.0 \%$ \\
\hline $55-3 D$ & $77.26 \%$ & $21.77 \%$ & $0.93 \%$ & $0.05 \%$ & $<0.50$ & $<0.01$ & $<0.01$ & $<0.01$ & $100.0 \%$ \\
\hline $55-3 \mathrm{E}$ & $77.48 \%$ & $21.56 \%$ & $0.92 \%$ & $0.04 \%$ & $<0.50$ & $<0.01$ & $<0.01$ & $<0.01$ & $100.0 \%$ \\
\hline $55-3 \mathrm{~F}$ & $77.35 \%$ & $21.69 \%$ & $0.92 \%$ & $0.05 \%$ & $<0.50$ & $<0.01$ & $<0.01$ & $<0.01$ & $100.0 \%$ \\
\hline $56-3 A$ & $75.83 \%$ & $23.20 \%$ & $0.93 \%$ & $0.04 \%$ & $<0.50$ & $<0.01$ & $<0.01$ & $<0.01$ & $100.0 \%$ \\
\hline $56-3 B$ & $76.46 \%$ & $22.56 \%$ & $0.92 \%$ & $0.05 \%$ & $<0.50$ & $<0.01$ & $<0.01$ & $<0.01$ & $100.0 \%$ \\
\hline $56-3 C$ & $76.82 \%$ & $22.22 \%$ & $0.92 \%$ & $0.05 \%$ & $<0.60$ & $<0.01$ & $<0.01$ & $<0.01$ & $100.0 \%$ \\
\hline $56-3 D$ & $76.89 \%$ & $22.09 \%$ & $0.92 \%$ & $0.10 \%$ & $<0.50$ & $<0.01$ & $<0.01$ & $<0.01$ & $100.0 \%$ \\
\hline $56-3 E$ & $76.82 \%$ & $22.18 \%$ & $0.93 \%$ & $0.06 \%$ & $<0.50$ & $<0.01$ & $<0.01$ & $0.01 \%$ & $100.0 \%$ \\
\hline $56-3 \mathrm{~F}$ & $76.64 \%$ & $22.37 \%$ & $0.92 \%$ & $0.07 \%$ & $<0.50$ & $<0.01$ & $<0.01$ & $<0.01$ & $100.0 \%$ \\
\hline CD-1 & $76.64 \%$ & $22.37 \%$ & $0.92 \%$ & $0.07 \%$ & $<0.50$ & $<0.01$ & $<0.01$ & $<0.01$ & $100.0 \%$ \\
\hline HD-1 & $77.26 \%$ & $21.77 \%$ & $0.91 \%$ & $0.06 \%$ & $<0.50$ & $<0.01$ & $<0.01$ & $<0.01$ & $100.0 \%$ \\
\hline OD-1 & $77.25 \%$ & $21.76 \%$ & $0.92 \%$ & $0.07 \%$ & $<0.50$ & $<0.01$ & $<0.01$ & $<0.01$ & $100.0 \%$ \\
\hline 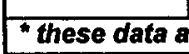 & preminin & y since & QA req & ments are n & Iete & & & & \\
\hline & & & & & & & & & \\
\hline
\end{tabular}


Table 4. Dec. 2, 1997 gas sample analyses determined by analytical gas mass spectrometry.* All results are expressed in mole (volume) percent.

\begin{tabular}{|c|c|c|c|c|c|c|c|c|c|}
\hline Sample Name & Nitrogen & Oxygen & Argon & Carbon Dioxide & Carbon Monoxide & Methane & Helium & Hydrogen & Total $\%$ \\
\hline$\# 54-1 A$ & $77.48 \%$ & $21.55 \%$ & $0.95 \%$ & $0.02 \%$ & $<0.50 \%$ & $<0.01 \%$ & $<0.01 \%$ & $<0.01 \%$ & $100.0 \%$ \\
\hline$\# 54-1 B$ & $76.94 \%$ & $22.07 \%$ & $0.94 \%$ & $0.04 \%$ & $<0.50 \%$ & $<0.01 \%$ & $<0.01 \%$ & $<0.01 \%$ & $100.0 \%$ \\
\hline$\# 54-1 C$ & $76.98 \%$ & $22.02 \%$ & $0.94 \%$ & $0.06 \%$ & $<0.50 \%$ & $<0.01 \%$ & $<0.01 \%$ & $<0.01 \%$ & $100.0 \%$ \\
\hline$\# 54-1 D$ & $77.38 \%$ & $21.65 \%$ & $0.92 \%$ & $0.05 \%$ & $<0.50 \%$ & $<0.01 \%$ & $<0.01 \%$ & $<0.01 \%$ & $100.0 \%$ \\
\hline$\# 54-1 E$ & $77.19 \%$ & $21.86 \%$ & $0.93 \%$ & $0.02 \%$ & $<0.50 \%$ & $<0.01 \%$ & $<0.01 \%$ & $<0.01 \%$ & $100.0 \%$ \\
\hline$\# 54-1 F$ & $77.15 \%$ & $21.86 \%$ & $0.92 \%$ & $0.07 \%$ & $<0.50 \%$ & $<0.01 \%$ & $<0.01 \%$ & $<0.01 \%$ & $100.0 \%$ \\
\hline & & & & & & & & & \\
\hline \#54-3A & $77.49 \%$ & $21.55 \%$ & $0.93 \%$ & $0.04 \%$ & $<0.50 \%$ & $<0.01 \%$ & $<0.01 \%$ & $<0.01 \%$ & $100.0 \%$ \\
\hline$\# 54-3 B$ & $76.92 \%$ & $22.11 \%$ & $0.92 \%$ & $0.05 \%$ & $<0.50 \%$ & $<0.01 \%$ & $<0.01 \%$ & $<0.01 \%$ & $100.0 \%$ \\
\hline$\# 54-3 C$ & $76.79 \%$ & $22.15 \%$ & $0.93 \%$ & $0.13 \%$ & $<0.50 \%$ & $<0.01 \%$ & $<0.01 \%$ & $<0.01 \%$ & $100.0 \%$ \\
\hline \#54-3D & $77.26 \%$ & $21.76 \%$ & $0.91 \%$ & $0.07 \%$ & $<0.50 \%$ & $<0.01 \%$ & $<0.01 \%$ & $<0.01 \%$ & $100.0 \%$ \\
\hline$\# 54-3 E$ & $77.14 \%$ & $21.73 \%$ & $0.91 \%$ & $0.22 \%$ & $<0.50 \%$ & $<0.01 \%$ & $<0.01 \%$ & $<0.01 \%$ & $100.0 \%$ \\
\hline$\# 54-3 F$ & $77.52 \%$ & $21.50 \%$ & $0.91 \%$ & $0.07 \%$ & $<0.50 \%$ & $<0.01 \%$ & $<0.01 \%$ & $<0.01 \%$ & $100.0 \%$ \\
\hline$\# 54-5 A$ & $77.00 \%$ & $22.03 \%$ & $0.93 \%$ & $0.05 \%$ & $<0.50 \%$ & $<0.01 \%$ & $<0.01 \%$ & $<0.01 \%$ & $100.0 \%$ \\
\hline$\# 54-5 B$ & $76.93 \%$ & $22.09 \%$ & $0.93 \%$ & $0.05 \%$ & $<0.50 \%$ & $<0.01 \%$ & $<0.01 \%$ & $<0.01 \%$ & $100.0 \%$ \\
\hline$\# 54-5 C$ & $77.46 \%$ & $21.57 \%$ & $0.92 \%$ & $0.06 \%$ & $<0.50 \%$ & $<0.01 \%$ & $<0.01 \%$ & $<0.01 \%$ & $100.0 \%$ \\
\hline$\# 54-5 D$ & $77.21 \%$ & $21.82 \%$ & $0.92 \%$ & $0.05 \%$ & $<0.50 \%$ & $<0.01 \%$ & $<0.01 \%$ & $<0.01 \%$ & $100.0 \%$ \\
\hline$\# 54-5 E$ & $77.14 \%$ & $21.87 \%$ & $0.92 \%$ & $0.07 \%$ & $<0.50 \%$ & $<0.01 \%$ & $<0.01 \%$ & $<0.01 \%$ & $100.0 \%$ \\
\hline$\# 56-1 \mathrm{~A}$ & $77.85 \%$ & $2122 \%$ & $0.90 \%$ & $0.02 \%$ & $<0.50 \%$ & $<0.01 \%$ & $<0.01 \%$ & $<0.01 \%$ & $100.0 \%$ \\
\hline$\# 56-1 B$ & $77.50 \%$ & $21.54 \%$ & $0.91 \%$ & $0.06 \%$ & $<0.50 \%$ & $<0.01 \%$ & $<0.01 \%$ & $<0.01 \%$ & $100.0 \%$ \\
\hline$\# 56-1 \mathrm{C}$ & $77.64 \%$ & $21.39 \%$ & $0.91 \%$ & $0.06 \%$ & $<0.50 \%$ & $<0.01 \%$ & $<0.01 \%$ & $<0.01 \%$ & $100.0 \%$ \\
\hline \#56-1D & $75.02 \%$ & $23.89 \%$ & $1.01 \%$ & $0.08 \%$ & $<0.50 \%$ & $<0.01 \%$ & $<0.01 \%$ & $<0.01 \%$ & $100.0 \%$ \\
\hline$\# 56-1 E$ & $77.63 \%$ & $21.42 \%$ & $0.92 \%$ & $0.03 \%$ & $<0.50 \%$ & $<0.01 \%$ & $<0.01 \%$ & $<0.01 \%$ & $100.0 \%$ \\
\hline$\# 56-3 A$ & $78.12 \%$ & $20.94 \%$ & $0.92 \%$ & $0.02 \%$ & $<0.50 \%$ & $<0.01 \%$ & $<0.01 \%$ & $<0.01 \%$ & $100.0 \%$ \\
\hline$\# 56-3 B$ & $77.43 \%$ & $21.59 \%$ & $0.91 \%$ & $0.07 \%$ & $<0.50 \%$ & $<0.01 \%$ & $<0.01 \%$ & $<0.01 \%$ & $100.0 \%$ \\
\hline$\# 56-3 \mathrm{C}$ & $77.66 \%$ & $21.39 \%$ & $0.92 \%$ & $0.03 \%$ & $<0.50 \%$ & $<0.01 \%$ & $<0.01 \%$ & $<0.01 \%$ & $100.0 \%$ \\
\hline$\# 56-3 D$ & $77.56 \%$ & $21.48 \%$ & $0.92 \%$ & $0.04 \%$ & $<0.50 \%$ & $<0.01 \%$ & $<0.01 \%$ & $<0.01 \%$ & $100.0 \%$ \\
\hline$\# 56-3 E$ & $77.48 \%$ & $21.57 \%$ & $0.92 \%$ & $0.03 \%$ & $<0.50 \%$ & $<0.01 \%$ & $<0.01 \%$ & $<0.01 \%$ & $100.0 \%$ \\
\hline OD-1 & $77.36 \%$ & $21.65 \%$ & $0.92 \%$ & $0.06 \%$ & $<0.50 \%$ & $<0.01 \%$ & $<0.01 \%$ & $<0.01 \%$ & $100.00 \%$ \\
\hline HD-1 & $77.12 \%$ & $21.86 \%$ & $0.93 \%$ & $0.09 \%$ & $<0.50 \%$ & $<0.01 \%$ & $<0.01 \%$ & $<0.01 \%$ & $100.00 \%$ \\
\hline
\end{tabular}

* these data are preliminary since the QA requirements are not complete 


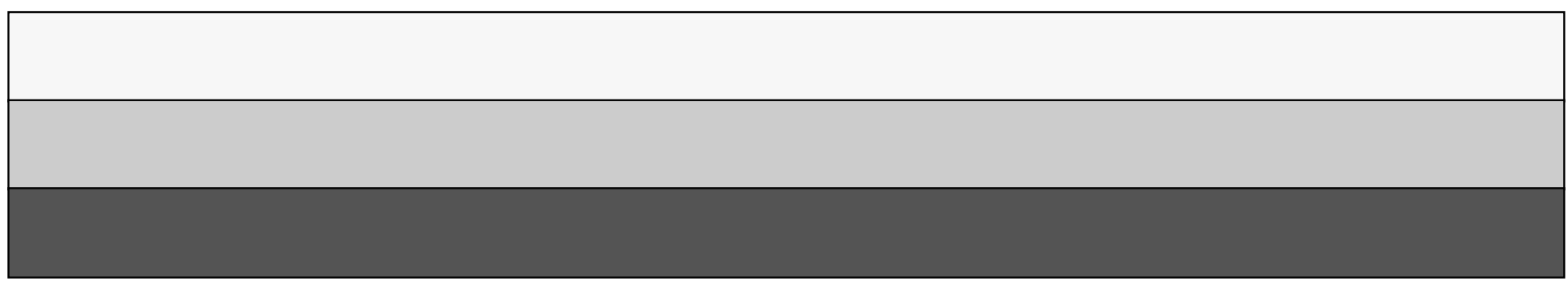

